\title{
Acculturation Theory, Cultural competency and Learning from \\ Differences: Reflections from a European Short Student Mobility
}

Program

\begin{abstract}
There is a growing recognition that in an increasingly differentiated social environment it is important for social workers to be prepared to intervene in multi-diversified and multicultural contexts, so as to promote inclusion, respect and empowerment. On this account, mobility and full immersion programs appear to contribute the most promising professional learning opportunities. However, full immersion programs are emotionally and cognitively very demanding, sometimes even exacerbating prejudice and racism; this has led to ongoing debates as to which strategies can safeguard the effectiveness of such programs.
\end{abstract}

This paper draws on the theory of acculturation inspired by from Berry (2006) to enable a deeper understanding of how full immersion programs can educate to diversity in social work, and of the learning processes which can occur when confronting diversity. The reflection focuses on written feedback from and focus groups with students who participated in a short mobility project. Findings show how self-reflective practice, which acknowledges emotional journeys including what are usually considered negative reactions, is a necessary pre-condition for successfully transferring experiences of relating to cultural differences - as in the mobility program - to professional skills.

Keywords: cultural competence, globalization, social work education, Critical reflection, international social work 
There is an established recognition of the importance of educating social workers to intervene in a diversified and multicultural world. As a result, there is a tension for social work programs in Europe and in the western world towards offering courses that include multiculturalism and social sensitivity in their curricula Harrison, and Turner, 2011 Jani et al., 2016; Sousa and Almeida, 2016); in many contexts it is mandatory for social work courses todevote time to helping students to develop the so-called 'cultural competence' as well as critical professional identities in multicultural societies which are deeply affected by globalization processes (Chambon et al., 2014; Dean, 1981; Nadan and Ben-Ari 2012; Author own, 2017). Among the most recognized means to achieve these goals are international field placements and student mobility programs, as part of international cooperation within joint projects (Köngeter, Altissimo, JakobyHerz, \& Schröer, 2015; Author own, 2012). Overseas and international programs often represent an important opportunity for participants to learn to negotiate feelings of otherness from the point of view of a cultural minority (Barlow, 2007; Crabtree, Parker, Azman, \& Carlo, 2014; Engstrom \& Jones, 2007; Pawar, Hanna, \& Sheridan, 2004). The main reflection presented in this paper is based on a short international mobility program, and stemmed from a discussion between staff members on how to proceed in making these experiences formative. In full immersion programs students find themselves in a position which is not unlike being part of minority groups. Such experiences may therefore give rise to professional and personal tensions, as they consist of full immersion contact with different worlds, thus deeply affecting the persons involved. Such experiences challenge the participants' values and principles as well as their ways of being and feeling, and are therefore very testing experiences which might jeopardize their aims, namely resistance and rejection (Chambon, 2013; Mathiesen \& Lager, 2007; Nagy \& Falk, 2000; Ranz, Author own, 2015; Wiles, 2013; $\mathrm{Xu}, 2006)$. 
Therefore, the mere fact of participating in a full immersion experience and being in contact with diversity does not in itself guarantee that a training program will successfully develop open mindedness and anti-oppressive attitudes, or cultural competences themselves. This paper is based on a reflection over a short student mobility project, and aims to better conceptualize the learning processes resulting from such projects. We maintain that learning processes could be better understood through the lens of acculturation theory. Our goal is to contribute to a better grasp of cultural competence, as well as to broaden and deepen our knowledge of best practices for their development.

\section{Cultural Competence, Acculturation Theory and Students Mobility: a}

\section{Literature Review}

Cultural competence can be understood as an ongoing process whereby one gains awareness and appreciation of cultural diversity, and an ability to work sensitively, respectfully, and proficiently with those from diverse backgrounds. Azzopardi and McNeill, (2016) claimed that "cultural competence includes the trajectory of knowledge development and integration of critical knowledge for practice" (p. 283); thus the ongoing process, which constitutes cultural competence itself, consists of three characteristics of cross-cultural competence : (a) counselor's awareness of his or her own assumptions, values, and biases, (b) counselor's awareness of the client's worldview, and (c) culturally appropriate interventions - all of which develop across three dimensions: knowledge, beliefs and attitudes, and skills (Sue, Ivey, \& Pedersen, 1996).

The idea that professionals should be culturally competent when operating in multicultural settings is widely consensual and has received vast scholarly attention, 
especially in discussions about international and global social work education and international field placement (Healy, 2008). As such, cultural competence serves as a key argument when advocating the importance and necessity of implementing international content in social work education and developing congruent educational programs.

Cultural competence, however, has been the subject of many discussions and debates, to the point of being defined as so vague and generic a concept that it should be discarded. Among the main criticisms, we particularly underline here that culture cannot be intended only as connected to ethnic groups, but has to be related to all differences in society (Jani et al 2016, Willis, 2017); that it is dynamic and ever-changing, and that there are relevant individual differences within ethnic and subculture groups. What emerges, therefore, is that only acquiring knowledge cannot be the answer (Jani et al. 2016). *Cultural competence - if the term is still meaningful, as some have redefined it as culture humility (Fisher-Borne 2015), refers to changes in attitude or mindset in relating to differences in society which take into account the term's related power dimensions. In a sense, the theme of cultural competence shifts from the focus on cognitive knowledge of differences or special abilities, towards considering the complex processes for dealing with differences and multiculturalism not only in interpersonal encounters, but in the wider society as well ( Sousa et Almeida, 2016).

It is within this perspective that the processes of acculturation can be relevant to understanding cultural competences, therefore to how subjects, within a social context, not merely relate to as yet unknown differences but also let themselves be changed by such encounters. Acculturation has been conceptualized by Berry (e.g., 1980; 2003) as a process of cultural and psychological change that follows intercultural contact in a multicultural society. Acculturation usually refers to the processes of coming to terms with a multicultural environment mainly for the purposes of building or adapting to a 
new life, as a result of processes of migration (although acculturation does not refer just to the incoming subjects, but to all incoming and receiving populations). The acculturation process involves the change, or lack of change, that occurs as the result of contact between two distinct cultures (Redfield, Linton, \& Herskovits, 1936). Berry (e.g., 1980; 2003) sees this as a bilateral process in which two orthogonal acculturation orientations toward the host and home cultures combine to produce four possible acculturation strategies. These strategies comprise: assimilation (accept host and reject home culture); separation (reverse of assimilation); integration (accept and connect both host and home cultures); and marginalization (reverse of integration). According to Berry's framework, integration may be the most adaptive strategy and marginalization the least adaptive. Since this model was first introduced, it has been widely used to empirically examine acculturation and its relationship to mental health status, family values, ethnic identity, and so forth (e.g., Constantine, Okazaki, \& Utsey, 2004; Lieber, Chin, Nihira, \& Mink, 2001; Ward \& Chang, 1997). Connected to this framework was the identification of developmental phases undergone when in significant contact with diversity (Oberg, 1960). The first, the so-called honeymoon phase, corresponds to a process not unlike falling in love with the new culture, and would correspond to assimilation: the person thinks that the new culture is perfect and better than their original one. The second phase, often termed culture shock, is seen as the opposite. The term "culture shock" is frequently used to describe how people react to novel or unaccustomed situations. As such, 'culture shock' designates a normal human response to an alien cultural environment, which includes affective, behavioural and cognitive components of cross-cultural interaction (Bochner, 2003; Mumford, 1998). As Oberg (1960) puts it, persons feel as fish out of water, negatively comparing what they meet with familiar situations, and feel frustration about minor occurrences. Culture shock thus entails a criticism of aspects of the host county which is not based on 
understanding: the person here does not try to grasp the differences, but rather judges them unfavorably, comparing them with the home culture they miss and they totally identify with (D’Souza et al. 2016).

The phases that follow, which Berry would define as integration, are characterized by a developing understanding of and interest in the differences. In positive settings and circumstances, people develop the ability to grasp the meaning of situations in different contexts. This produces a change in mentality, and, in longer sojourns, an identity change, so that it is possible to identify a reverse culture shock when people return to their country of origin.

In the literature, processes connected to acculturation have been identified in social work as well. Several authors have identified in student mobility an initial position that can be defined as honeymoon (Anukrati, 2016; Ritchie, 2009): the students feel excitement, fascination, and optimism, and are thus less engaged in a critical reflection process which may examine in depth the complexity of what they are experiencing (Kim, 2001).

Several studies have then revealed that in multicultural and international encounters experienced by social workers and social work students, there is an unconscious regression to conservative and even nationalistic perspectives (Chambon 2013; Wiles 2013), leading to devaluing indigenous knowledge (Tsang \& Yan, 2001). In addition, research findings show that the majority of international students express distress and experience cultural shock (Pyvis \& Chapman, 2005; Zhou et al., 2008), at least at the beginning of their international sojourns, as a result of being far from their home culture (Belford, 2017). Others have shown that students and social workers who are doing field practice with "others", in local contexts or abroad, have reported a wide range of intense emotional responses which include anger, guilt, frustration, anxiety, shame, a prevailing sense of being misunderstood and silenced, and potentially intensified 
apologetic attitudes (Barlow, 2007; Lough, 2009; Matthew \& Lough, 2017; Ranz, 2015). These reactions are usually recognized as indicative of a transformation process during which students re-evaluate and challenge their original attitudes, beliefs and worldviews (Barlow, 2007; Lager, Mathiesen, Rodgers, \& Cox, 2010; Matthew \& Lough, 2017; Taylor, 1994); such reactions might moreover re-enact previous socially traumatic situations as being neglected, living in poor environments, being underprivileged and marginalized.

Many of these studies emphasize that students need help, such as counselling or peer support, in dealing with cultural shock and 'honeymoon' attitudes in order to be able to learn while participating in mobility programs, and to develop professional skills and competences as intended (Presbitero, 2016). Although this argument is well documented in the literature on social work education (Author own, 2014; Ranz, 2015), most studies concentrate on how to facilitate adaptive behaviors (Sharner and Young, 2015).

Fewer studies have addressed the acculturation dynamic among social work students as a formative process, when facing cultural diversity either in mobility or in practice placement. What we maintain here is that the process of experiencing and reflecting on the honeymoon phase, culture shock and integration has a formative value. Undertaking the emotional journey, which accompanies and strongly influences students' cognitive and experiential learning processes, is not merely part of the adaptation: it is a necessary component in developing an ability to understand, recognize, and relate, as well as form a critical attitude towards cultural differences.

\section{The Method}


The argument on the relevance of acculturation in building cultural competences is based on our experience as academic staff members belonging to different institutions in different countries, on a three year Tempus program, TachyWe. The project was coordinated by a German university and included eight Universities and Colleges within five European countries: Germany, Ireland, Israel, Italy and Russia. The goal of the program was to internationalize training and promote cultural competences for social work in the field of child and youth welfare. A relevant part of this program consisted in organizing student exchanges. The latter consisted of intensive short study visits (15 days) including study periods, lectures, various meetings with practitioners, visits to social services, and discussions with peers and experts. The visits were short so as to allow students, since most were already working in social services, to participate, as well as to be able to handle language issues with the support of hosting students, as only one English-speaking country participated in the project.

We analyzed data resulting from written feedback and three online focus groups with participants to the program. In the written feedbacks students were asked to address several topics such as their motivation to participate in the program, what they did learn, if they had been able to identify universal issues in child protection, strengths and weaknesses of the program. All students should have produced a written feedback, but due to the difficulties of many students to write in a foreign language in several cases staff accepted just oral feedbacks. We had written feedbacks from 19 students: 14 females and 5 males who were attending different degrees programs: 7 were $\mathrm{PhD}$ students, 9 were attending a Master, and 4 were Bachelor students. As regards their nationality, 10 participants were from Israel, 4 from Russia, 3 from Italy, and 2 from Germany. As for the three focus groups, they were conducted through Skype from Italy by two university staff; 26 students participated ( 22 female and 4 male; 12 from Israel, 11 from Russia, 2 from Germany, and 2 from Italy). The students were prevalently 
Master and $\mathrm{PhD}$ students, but 3 Bachelor students also participated. The program was not initially intended for undergraduate, but the team decided to accept them in the mobility program, as long as they had previously had work experiences in the field of child and youth work. As previously mentioned, the majority of participants were practicing social work while studying. As 8 students provided both feedback and participated in a focus group, in total we have data from 37 of the 41 students who participated in the mobility program. The Irish students did not contribute any feedback, because they were unable to participate in the mobility due to organizational issues. A first report on the students' feedback (Authors et al, 2015) provided us with the bases for a reflection on the nature of the learning which takes place during short mobility programs. The first step was conducting an analysis of the emerging theme using a program for qualitative data analysis (QSR Nvivo 11). This inductive phase of data analysis produced numerous codes and subcodes (Liamputtong \& Ezzy, 2005). From there it became apparent how Berry's theory on acculturation could have been relevant to understand the learning process taking place, and we conducted deductive content analysis of the data; the texts were selectively analyzed in order to explore the participants' reactions to meeting a different world.

Our study undergo all the limits and strengths of qualitative research, in terms of the validity and generalizability of the outcomes. Particularly one of the main issues in this study consists of the involvement of the authors in the exchange project, which qualifies this as an insiders research (Humphrey, 2012 The main risk here is the taken for granted knowledge, to make assumptions and lose important information. This can be seen as a limit, and it was quite complex to reflexively deal with personal experiences with students while analyzing the data. At the same time having accompanied the students (not just in this project but also in others) and knowing directly the context, as many 
underline (Teusner, 2016), represents a strength and in our case allowed a deeper understanding of students' accounts.

As regards ethical issues, the guidelines of the university's Board of Ethics were followed at all times; participants were informed and accepted that their feedback would be used for research and publication; their contributions have been anonymized.

\section{Phases of Acculturation in the Students' Accounts}

Considering the positions identified in acculturation (Berry, 2003), the first attitude we were able to identify in students' accounts appears to be similar to what has been defined as the honeymoon phase. As anticipated, it consisted of a general but superficial enthusiasm for the new reality. The enthusiasm seems to be based on a shallow engagement with the world students were immersed in, leading to meetings and visits being experienced as a kind of tourism, with visiting students observing the mere surface or facade of social services and social interventions they were shown. In this case observations were usually generally very positive, based often on favourable comparisons with the home country:

"I was impressed that relative to Israel ... it seems that South Tyrol has more resources to deal with children at risk. The conditions in the various institutions (modern buildings, wide open spaces and landscapes), the number of children in each facility (up to 8 ) and the number of staff in relation to the number of children in institutions are different compared to Israel." (Israeli student)

There are many extremely positive comments and often these students thought that what was happening in the visited country as far as social services were concerned was definitely better compared to their country:

"My personal spontaneous reactions for the most part reflect my feelings and emotions: love and belief in your country, love for children and a host of other things. No doubt, Israel is an incredible and patriotic country which is strong in spirit.” (Russian student) 
"I was very impressed to see the cultural sensitivity, as I wrote above. In Israel we have a lot of minorities (Arabic, Russian, Ethiopian...) and I don't speak any of those languages, and also most of the Israeli population don't speak one of them. When I saw that in the host country all social workers spoke two languages it made me feel a bit ashamed that in my country this doesn't exist." (Israeli student)

In these particular cases, students seem to notice only positive aspects and do not perceive problems, somehow remaining on the surface; for instance, their observations do not seem to consider the underlying difficulties and conflicts within the area. The crucial point remains that the comments are based on a comparison with the home country and there are no signs of an understanding of the different context.

Last but not least, a feature of the 'honeymoon' approach we noticed was the attention given to aspects perceived by students as folklore - which were in fact indications of a tragedy occurring in the country. This is exemplified through a student asking to be photographed with a group of young armed soldiers in Israel, as a souvenir. Less dramatically, other students made comments on the landscape or the mountains and so forth, providing a picture close to a postcard.

We need to stress here that this 'honeymoon' attitude is not to be considered negatively as it seems a natural reaction within the process of engaging with diversity, and it needs to be processed in order for the experience to be formative.

Naturally, any superficial observations on the part of the participating students can be connected to superficial explanations by the host in a two-way process. On the one hand, we can see students who are keen to have a positive attitude towards the new and exotic country, and on the other hand a hosting group who tend to present the better 
aspects of their services, and who appear unwilling to discuss the more negative traits in their social realities: the visit is short and the hosting students and staff want to make a good impression.

Some students with a more critical mindset perceived this attitude in their hosting group:

"I also experienced strategies for avoiding questions and critique, and transferring the process to another day of the week and then just focusing on some of the questions and ignoring others." (Italian student)

Other students noticed the seeming existence of taboo subjects:

"In different situations, it was not easy for us to confront our feelings with the partners. We think this was connected to the high tensions present in the country at that time. We felt that the conflict ... the life conditions... were like taboo issues." (Italian student)

Others noticed that it was not possible for them to grasp the reality of social services. As an Israeli student put it: 'we were in a show, not reality. Best social services, best kindergarten...'

The second type of comments we identified are negative and contain criticisms. They refer to experiencing something not unlike cultural shock as the negative evaluation is based on a comparison of the familiar with the unfamiliar*. Although the negative comments and feelings were not all-encompassing as in typical culture shock, occasionally students expressed negative feelings and impressions, sometimes in a judgmental way which is considered typical of the crisis in culture shock. An example of this was a student who generalized from a few observations in a specific context and was negatively struck by the fact that in Israel children would sleep on the floor:

"Student: I was in Israel. Children sleep on the floor without bed (frames). It's not good.

Facilitator: Were you able to say this? 
Student: Yes.

Facilitator: What did they answer?

Student: That it's their tradition in Israel.” (Russian student)

This may well have been the answer; however the exchange appears odd as certainly it is far from customary for children to sleep on the floor in Israel. Most likely, as in culture shock, the student seems to have been very negatively affected by some experiences: having seen a case of children sleeping on the floor (which she sees as not good) she may have misunderstood the answer generalzing from the specific case (In Israel children sleep on the floor). This generalization of traits deemed as negative as we have seen, is another typical trait of culture shock.

In another case, generally critical conclusions were drawn through the limited experience of the country. The student concerned was convinced, on the basis of a field visit, that in Italy there was no community work:

"As a community social worker I wondered why social workers (in Italy) do not promote and develop services? Doesn't the community need such assistance? I was engaged with these questions because I think that my most significant role as a social worker is to promote and assist in developing community capacity and creating an independent community, a community that won't need social work interventions and can manage with its own assets." (Israeli student)

Here it emerges that on the cognitive level there is a criticism that derives from a comparison with the home situation, which is perceived as good. As in culture shock the negative evaluation does not stem from an understanding of social work in a different country, but from the fact that there is a difference from what is customary in the home country.

Maybe the best example of culture shock comes from a student who was strongly negatively affected by the treatment of disabled children in a classroom in Italy. She was particularly interested in children with disabilities, thus a visit was specially organized for her to observe how a child with disabilities was included in a mainstream 
school. The student refers in her feedback that she was shocked by how badly the child was treated: the child was in the classroom with the other children, but was not able to participate fully, and was not given the necessary specialist attention and training. In her feedback the student stressed:

"It's okay to have a disabled child in a general class, but he has problems and needs! You cannot stop helping them just to have society's principle of inclusion maintained. In Israel, there are special classes for disabled children.

Knowing the field in Israel, I knew that the goals of individual child's rehabilitation may be often in conflict with the needs of the society. Does the Italian society's focus on inclusion come at the cost of reduced individual rehabilitation?! (sic)" (Israeli student)

We will return to this example and its development, as it shows how open discussion and reflection can support the processing of those negative feelings, thus enabling learning for both the hosting and the visiting subjects. This provides the basis for activating a mental journey akin to a positive acculturation, in the sense that students and staff, both visiting and incoming, have the opportunity to critically integrate their experiences and develop new creative ideas.

Again, as with the honeymoon phase, it should be underlined that culture shock is not in itself negative, being in fact a step in relating to diversity. Considering those reactions through the lens of acculturation theory leads to a new understanding. Such reactions become problematic only if not processed and elaborated, constituting in fact stages in an emotional journey that led participants to more critically open stances which enabled them to better understand and analyze critically what they had encountered. This mental and emotional process may then allow the development of new ideas in relation to their home contexts. In a student's words:

The basis should be trying to understand other approaches, seeing benefits and weaknesses and, after understanding another perspective, thinking of possible improvements (in your country) (German student). 
The best example of this journey was probably the one presented above, regarding the student who was very critical of the treatment of children with disabilities in Italian schools. This student explicitly refers to this mental and emotional journey. As indicated, the student's experience in a primary school class provoked a strong negative reaction. The student discussed her feelings in-depth, and she communicated, albeit with some difficulties, her strong criticism of the Italian system. However, her written feedback shows how her views underwent change whilst in Italy:

"I was against the Italian policy of inclusion (for children with disabilities) at first, but in the end I got excited about it...We were able to raise this issue openly... I have doubts whether children with special needs in integrated educational settings get the best service but the difference made me think about the limits of 'specialised schools'." (Israeli student)

The student reports that she works with autistic children and this experience changed her intervention approach.

A further example from a German student highlights how integration can take place:

"In Germany a large percentage of children in substitute care are placed in residential care facilities with an institutional background. Getting deeply in touch with the practice of foster care and its benefits made me rethink my perspective. The different point of view made me realized that institutional care in Germany must be sensitive to actually meet the needs of the children who are placed outside of their family of origin." (German student)

The above are quite good examples of change that emerged through processing what could be seen as an element of culture shock. Such change may lead to new approaches, to challenge routine ways of dealing with issues both in the home country and hosting country - it may lead to not importing ready-made solutions, but to being inspired by the differences and perceiving potentially fruitful innovations. This interchange bears many similarities with what the acculturation process is about. Our analysis supports the hypothesis that even short full immersion experiences, when they allow students to be 
aware and reflective on the acculturation processes which take place, can strengthen their ability to connect in a non-oppressive way with, the different worlds and cultures social workers meet in their practice, as well as critically learn from them.

\section{Suggestions for organizing student mobility}

Reports and focus groups provided several suggestions on the key features that support the journey we have described. The first feature relates to preparation: both students and staff observed that the better training students had received, the better they were able to undergo the process successfully. Preparation thus entailed opportunities to discuss expectations and fears in coming into contact with a new country. What emerges in this regard is that student exchanges - particularly short exchanges - should be part of a wider program with a time devoted to preparation, and a time for critical analysis of the experience.

The second essential feature relates to opportunities for constant reflection on and discussion of student experiences. It was perceived as crucial that the hosting staff and students should benefit from formal as well as informal opportunities for discussion and, where appropriate, that they should be willing to elicit and discuss criticisms: this would best enable both incoming students and staff and students from the hosting institution to develop from their initial stances.

Informal meetings between students and with program staff were particularly appreciated, and should therefore be included in the organization of the mobility:

"One of the most positive aspects of the program was communication during breaks. I would like to point out that our conversations were rather efficient. That is why it would be beneficial for all participants of the practical training to spend more time together. Informal communication gives rise to very interesting discussions, ideas.” (Russian student)

Above all, what everybody found crucial was the two-way exchange process that provided opportunities both for incoming students to present and discuss how services 
were organized in their home countries, and to present and discuss examples of practice with local students and practitioners. As expressed by a student:

"It was the first experience in my life for me to participate in a program like this. I could speak with professionals of social welfare about children, about parents, about family. I could share with them my own experiences and I could see the experiences of people from different countries." (Israeli students)

Emotional and cognitive processes can thus be seen to take place in a climate of reciprocity and mutual learning, as emerged in a focus group:

"Student: It's important for the [people we] visit to hear about our work in Israel....It was good to exchange knowledge and exchange experiences. Facilitator: To talk, not only listen.

Student: To share, exactly." (Israeli student)

This last excerpt from a focus group seems to show very effectively how the concept of mutual learning in student mobility is deemed important in developing cultural competences in the most positive sense.

\section{Discussion and Concluding Remarks}

Universities and social work courses aim for social work professionals and students to develop cultural competences in acting in a world in which globalization dynamics seem particularly strong, and characterized by growing diversity, considerable mobility and forced population displacement. How we should best prepare practitioners has been the subject of many debates. Our analyses reveal, in line with other researches (Brown \& Brown, 2013; Ranz, 2015; Robinson et al. 2016; Jani et al. 2016), that such competences are enabled by processes which involve the whole person, showing similarities to what was defined by Berry $(1997 ; 2003)$ as acculturation process. As claimed by Rogler (1994), student acculturation is a process of changing cultural beliefs and values arising from exposure to the culture of the host country in which the students are studying. 
In addition, our analysis shows that reaching a culturally competent position, one which allows in-depth and respectful interactions with the 'other', involves undergoing stages which would appear at first glance as negative. As such, we can hypothesize that students as well as staff who took part in our study experienced and dealt with a contradiction: on the one hand their emotional stance, as described above, and on the other hand their professional knowledge and professional requirements for them to be accepting and non-judgmental when they encounter others, especially in unfamiliar environments.

Focusing on the participants' professional knowledge could in fact lead to considering both the 'honeymoon' and the disorientation anger of culture shock phases as unconstructive, because they entail superficial attitudes, or because they are characterized by rejection and judgmental attitudes towards what is perceived as different. However, students' feedback as regards their mobility experiences highlight how these are natural reactions when feeling personally challenged by cultural differences.

As such, studies and researches on acculturation processes can be of great relevance for the education and supervision of practitioners: spontaneous natural reactions do not need to be repressed or negatively valued, but rather to be processed for the experience to become formative.

Our second main point, which supports other research results (Bell \& Anscombe, 2012; Das \& Anand, 2014), is that the main means that proved useful in supporting such a process is related to creating space for reflection and discussion - a protected and accepting environment which allows the free expression of negative feelings and thoughts.

As shown by the results, the mobility experience becomes formative when students are firstly prepared, then accompanied during their intercultural experiences, and finally are 
able to discuss their experiences afterwards. This provides initial evidence of the effectiveness of the three phases in international programs as described for example by Author (2014) and Schwartz et al. (2011).

Another point, which is specific to mobility, is that processing the complex feelings and ideas which arise whilst experiencing cultural difference is definitely facilitated in a context where there is reciprocity and mutual learning as well as informal opportunities for social interaction (Author, own). Although in this paper we focus on students, in our view cultural competence journey needs to be travelled by all, not only by the students involved in mobility programs, but also by teaching staff supervisors, both in the hosting and home countries.

Our analyses point to the view that cultural competence could entail a more complex meaning: it does not merely involve being open or knowledgeable, but could additionally be equated to being familiar with and having experiences of the process of acculturation. This means knowing how to master reflectively the steps and phases that professionals and lay people undergo when relating meaningfully to difference. As such, possessing cultural competences would mean being prepared to recognize and process the natural responses which occur when relating to or being immersed in unfamiliar worlds, where familiar frames of reference have lost validity. As Jani et al. observe, 'culture is fluid and ever changing and, therefore, competence in a culture can never be permanently attained' (2016, p. 314).

As acculturation theory affirms, we need to underline that the stance of being open to change one's ideas in meeting with difference is one of the preconditions for avoiding oppressive relations, particularly when there is power imbalance. For this openness to become part of the professional mentality our reflection points to the relevance of full immersion programs, which need not take place abroad (Quinn-Lee and Olson- 
McBride, 2013). Even programs of short duration, if carefully organized, can provide the best environment for learning to deal with differences in a non-oppressive way.

\section{References}

Author own, (2012)

Author own, (2014)

Authors own et al, (2015)

Author own, (2017)

Anderson, J.R., \& Guan, Y. (2017). Implicit Acculturation and the Academic Adjustment of Chinese Student Sojourners in Australia, Australian Psychology, 1-11, doi: 10.1111/ap.12332

Anukrati, S. (2016). Educational Tourism: Strategy for Sustainable Tourism Development with reference of Hadauti and Shekhawati Regions of Rajasthan ,India, Journal of Knowledge Management, Economics and Information Technology, 5, 4, 117.

Azzopardi, C., \& McNeill, T.(2016) From Cultural Competence to

Cultural Consciousness: Transitioning to a Critical Approach to Working Across Differences in Social Work, Journal of Ethnic \& Cultural Diversity in Social Work, 25,4, 282-299, DOI: 10.1080/15313204.2016.1206494

Barlow, C. (2007). In the third space: A case study of Canadian students in a social work practicum in India. International Social Work, 50, 243-254. doi:

10.1177/0020872807073990.

Belford, N. (2017). International Students from Melbourne Describing Their CrossCultural Transitions Experiences: Culture Shock, Social Interaction, and Friendship Development, Journal of International Students, 7(3) , 499-521 . doi:

10.5281/zenodo.569941.

Bell, K. and A.W. Anscombe (2012) 'International Field Experience in Social Work: Outcomes of a Short-Term Study Abroad Programme to India', Social Work Education 32: 1032-47. doi.org/10.1080/02615479.2012.730143

Berry, J. W. (1997). Immigration, acculturation, and adaptation. Applied Psychology, 46, 5-34. http://dx.doi.org/10.1111/j.1464-0597.1997.tb01087.x.

Berry, J. W. (2003). How shall we all live together? In M. Luik (Ed.), Multicultural Estonia (pp. 3-11). Tallinn: Estonian Integration Foundation. 
Berry, J. W. (2006). Acculturation: A conceptual overview. In M. H. Borstein \& L. R. Cote (Eds.), Acculturation and parent-child relationships: Measurement and Development (pp. 13-29). Mahwah, NJ: Lawrence Erlbaum Associates.

Berry, J. W.,Kim,U., Minde, T.,\&Mok, D. (1987). Comparative studies of acculturative stress. International Migration Review, 21, 491_511.

Brown, L. (2008). The incidence of study-related stress in international students in the initial stage of the international sojourn. Journal of Studies in International Education, 12(1), 5-28. doi.org/10.1177/1028315306291587.

Brown, J. \& Brown, L. (2013). The international student sojourn, identity conflict and threats to well-being, British Journal of Guidance \& Counselling, 41, 4, 395_413. doi.org/10.1080/03069885.2012.729026

Brown, L. \& Holloway, I. (2008), "The initial stage of the international sojourn: excitement or culture shock?", British Journal of Guidance \& Counselling, 36, 1, 3349. doi.org/10.1080/03069880701715689.

Chambon, A. (2013). Recognising the other, understanding the other: A brief history of social work and otherness. Nordic Social Work Research, 3, 120-129. doi: $10.1080 / 2156857 X .2013 .835137$

Chambon, A. S., Johnstone, M., \& Köngeter, S. (2014). The circulation of knowledge and practices across national borders in the early 20th century: A focus on social reform organisations. European Journal of Social Work, 18, 495-510. doi: $10.1080 / 13691457.2014 .953041$

Crabtree, S.A., Parker, J., Azman, A. \& Carlo, D.P. (2014). Epiphanies and learning in a postcolonial Malaysian context: A preliminary evaluation of international social work placements, International Journal of Social Work, 75,6, 618-629. https://doi.org/10.1177/0020872812448491.

Das, C., \& Anand, J.C. (2014). Strategies for critical reflection in international contexts for social work students. International Social Work, 57, 109-120. doi.org/10.1177/0020872812443693

Dean, R. G. (2001). The myth of cross-cultural competence. Families in Society, 82, 623-630. doi: 10.1606/1044-3894.151.

D'Souza, C., Singaraju, S., Halimi, T., \& Sillivan Mort, G. (2016). Examination of cultural shock, inter-cultural sensitivity and willingness to adapt. Education + Training, 58(9), 906-925. https://doi.org/10.1108/ET-09-2015-0087 
Engstrom, D., \& Jones, L. P. (2007). A broadened horizon: the value of international social work internships. Social Work Education, 26(2), 136-150.

doi.org/10.1080/02615470601042631

Hall, C. M. (2010). Academic capitalism, academic responsibility and tourism academics: Or, the silence of the lambs? Tourism Recreation Research, 35, 3, $298-301$. doi.org/10.1080/02508281.2010.11081646.

Healy, M., L. \& Wairire, G.,G. (2014). Education for the global agenda: Internationally relevant conceptual frameworks and knowledge for social work education. International Journal of Social Work, 57, 235-247. doi: 10.1177/0020872813519463.

Huegler, N., K. Lyons and M. Pawar (2012) 'Setting the Scene', in K. Lyons, T. Hokenstad, M. Pawar, N. Huegler and N. Hall (eds) The SAGE Handbook of International Social Work, pp. 70-84. London: SAGE.

Humphrey, C. (2012). Dilemmas in doing insider research in professional education. Qualitative Social Work, 12(5), 572-586. https://doi.org/10.1177/1473325012446006

Jani, J. S., Osteen, P., \& Shipe, S. (2016). Cultural Competence and Social Work Education : Moving Toward Assessment of Practice Behaviors. Journal of Social Work Education, 52(3), 311-324. https://doi.org/10.1080/10437797.2016.1174634.

Kashima, E. S., \& Loh, E. (2006). International students' acculturation: Effects of international, conational, and local ties and need for closure. International Journal of Intercultural Relations, 30(4), 471-485. http://dx.doi.org/10.1016/j.ijintrel.2005.12.003

Kim, Y.Y. (2001). Becoming intercultural: An integrative theory of communication and crosscultural adaptation. Thousand Oaks, CA: Sage.

Köngeter, S., Altissimo, A., Jakoby-Herz, A., \& Schröer, W. (2015). Child and youth welfare in globalized societies: Migration in child and youth care - a transnational curriculum for social work courses. Transnational Social Review, 5, 73-78. doi:10.1080/21931674.2014.997086.

Lager, P. B., Mathiesen, S. G., Rodgers, M. E., \& Cox, S. E. (2010). Guidebook for international field placements and student exchanges. Alexandria, VA: CSWE Press.

Liamputtong, P., \& Ezzy, D. (2005). Qualitative research methods, Vol. 2nd. South Melbourne: Oxford University Press.

Lough, B.J. (2009). Principles of Effective Practice in International Social Work Field Placements, Journal of Social Work Education, 45, 3, 467-480. doi.org/10.5175/JSWE.2009.200800083

Mathiesen, S., \& Lager, P. (2007). A model for developing international student exchanges. Social Work Education, 26, 280-291. doi.org/10.1080/02615470601049867. 
Matthew, L.E., \& Lough, B.J. (2017). Challenges Social Work Students Encounter in International Field Placements and Recommendations for Responsible Management, Journal of Social Work Education, 53, 1, 18-36.

doi.org/10.1080/10437797.2016.1246268

Nadan, Y., \& Ben-Ari, A. (2012). What can we learn from rethinking

"multiculturalism" in social work education? Social Work Education: The International Journal, 32, 1089-1102. doi:10.1080/02615479.2012.723686.

Nagy, G. \& Falk, D. (2000). Dilemmas in international and cross-cultural social work education. International Social Work, 43, 49-60. doi.org/10.1177/a010520.

Oberg, K. (1960). 'Cultural Shock: Adjustment to New Cultural Environments'. Practical Anthropology, 7, 177-182. doi/10.1177/009182966000700405

Pawar, M., Hanna, G. \& Sheridan, R. (2004). International social work practicum in India. Australian Social Work, 57, 223-236. doi: 10.1111/j.1447-0748.2004.00150.x

Payne, M. \& Askeland, G. A. (2008). Globalization and International Social Work. Aldershot: Ashgate

Tice, J. C. \& Long, D. D. Eds. (2009). International social work: Policy and practice. Hoboken, NJ: Wiley. http://www.jstor.org/stable/23044385.

Presbitero, A. (2016). Culture shock and reverse culture shock: The moderating role of cultural intelligence in international students' adaptation. International Journal of Intercultural Relations, 53(Supplement C), 28-38.

https://doi.org/10.1016/j.ijintrel.2016.05.004

Pyvis, D., \& Chapman, A. (2005). Culture Shock and the International Student 'Offshore'. Journal of Research in International Education, 4(1), 23-42. doi.org/10.1177/1475240905050289.

Quinn-Lee, L., \& Olson-McBride, L. (2013). The effect of domestic immersion experiences on levels of cultural competence. The Journal of Baccalaureate Social Work, 17, 119-132.

Ranz, R. (2015). A psycho-educational learning framework for international fieldwork abroad. International Social Work, Published online. doi:10.1177/0020872815594227. 
Ranz, R., \& Korin-Langer, L. (2018). Preparing international social work students to engage with unequal power relations, Social Work Education, doi: 10.1080/02615479.2018.1444158.

Redfield, R., Linton, R., \& Herskovits, M. J. (1936). Memorandum for the study of acculturation. American Anthropologist, 38(1), 149-152.

https://doi.org/10.1525/aa.1936.38.1.02a00330

Ritchie, B.W.(2009).School excursion management in national capital cities. In R. Maitland \& B. W. Ritchie (Eds.), City tourism: National Capital Perspectives (pp.185200). Oxfordshire, UK:CABI.

Robinson, M. A., Cross-denny, B., Lee, K. K., Rozas, M. W., Yamada, A., Allen, M., Yamada, A. (2016). Teaching Note - Teaching Intersectionality : Transforming Cultural Competence Content in Social Work Education. Journal of Social Work Education, 52(4), 509-517. https://doi.org/10.1080/10437797.2016.1198297

Rogler, L. H. (1994). International migrations: A framework for directing research. American Psychologist, 49, 701-708. https://doi.org/10.1037/0003-066X.49.8.701

Saunders, J. A., Haskins, M., \& Vasquez, M. (2015). Cultural competence: A journey to an elusive goal. Journal of Social Work Education, 51(1), 19-34.

https://doi.org/10.1080/10437797.2015.977124

Schwartz, K., L. Kreitzer, M. Lacroix, C.A. Barlow, L. McDonald, S. Lichtmannegger, M. Klassen, T. Orjasniemi and D. Meunier (2011). 'Preparing Students for International Exchanges: Canadian/EU Experiences', European Journal of Social Work 14: 421-34. doi.org/10.1080/13691457.2010.488213.

Sousa, P., \& Almeida, J. L. (2016). Culturally sensitive social work: promoting cultural competence. European Journal of Social Work, 19(3-4), 537-555.

https://doi.org/10.1080/13691457.2015.1126559

Schartner, A., \& Young, T. (2015). Culture Shock or Love at First Sight? In A. H. Fabricius \& B. Preisler (Eds.) Transcultural Interaction and Linguistic Diversity in Higher Education: The Student Experience. (pp. 12-33). London: Palgrave Macmillan UK. https://doi.org/10.1057/9781137397478_2.

Sue, D. W., Ivey, A. E., \& Pedersen, P. B. (1996). A theory of multicultural counseling and therapy. Pacific Grove, CA: Brooks.

Taylor, E.W. (1994). 'Intercultural Competency: A Transformative Learning Process', Adult Education Quarterly 44: 154-74. doi.org/10.1177/074171369404400303.

Tsang, A. K. T., \& Yan, M. C. (2001). Chinese corpus, western application: the Chinese strategy of engagement with western social work discourse. International Social Work, 44, 433-454. doi.org/10.1177/002087280104400404. 
Teusner, A. (2016). Insider research, validity issues, and the OHS professional: one person's journey. International Journal of Social Research Methodology, 19(1), 85-96. https://doi.org/10.1080/13645579.2015.1019263

White, R. (2006). Opportunities and challenges for social workers crossing borders, International Social Work, 49, 629-640. doi: 10.1177/0020872806066765.

Wiles, F. (2013). Not easily put into a box: Constructing professional identity. Social Work Education, 32, 854-866. doi.org/10.1080/02615479.2012.705273.

Willis, R., Pathak, P., Khambhaita, P., \& Evandrou, M. (2017). Complexities of cultural difference in social care work in England. European Journal of Social Work, 20(5), 685-696. https://doi.org/10.1080/13691457.2016.1255597

Xu, Q. (2006). Defining international social work: A social service agency perspective. International Social Work, 49, 679-692. doi.org/10.1177/0020872806069075

Zhou, Y., Jindal-Snape,D., Topping, K. \& Todman, J. (2008). Theoretical models of culture shock and adaptation in international students in higher education. Studies in Higher Education, 33(1), 63-75. doi: 10.1080/03075070701794833. 